V. 5, N. $11(2015)$

MULTITEMÁTICO

- SUMÁRIO

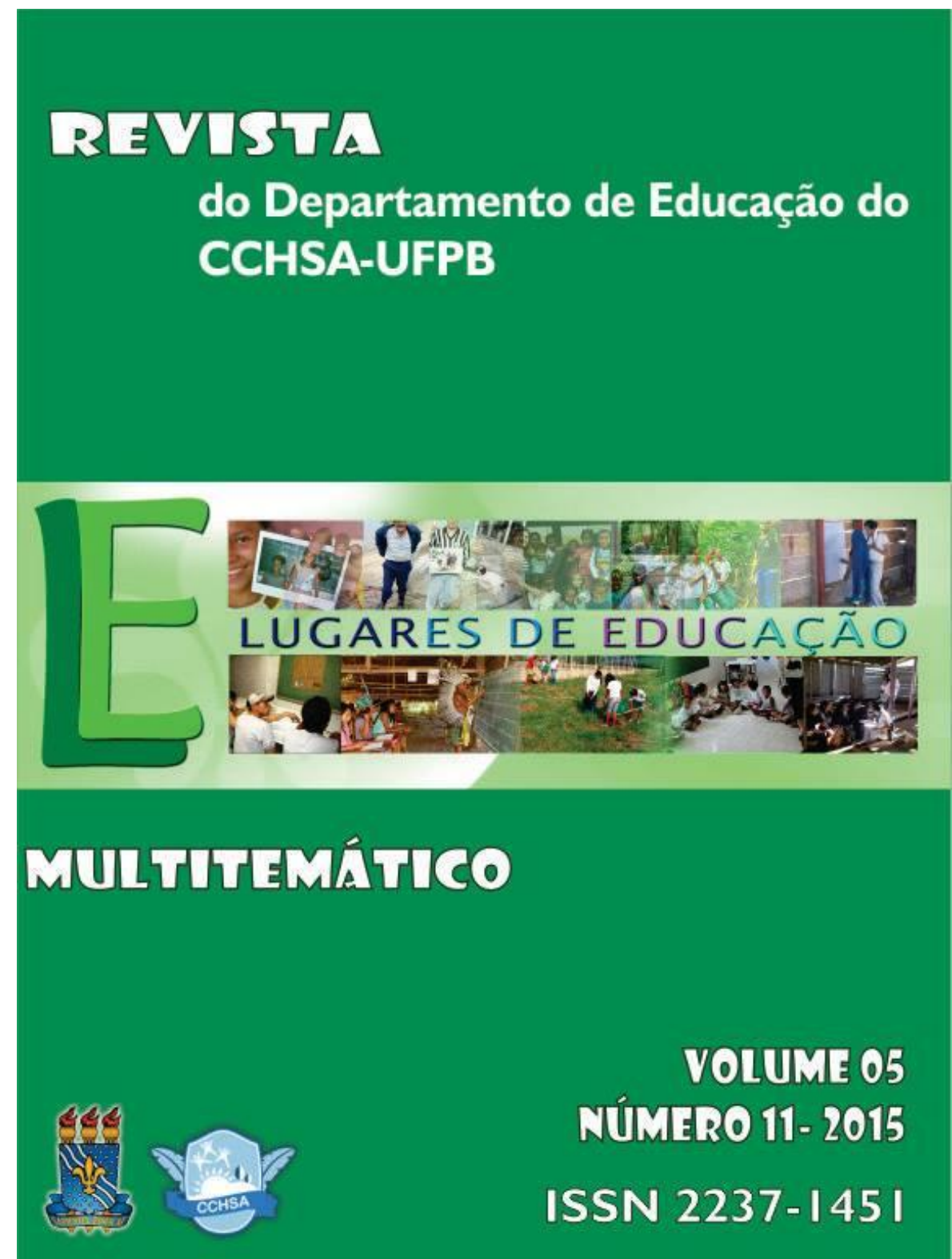

ORGANIZADORES

Silva - Editor-chefe

Evelin Carolyne de França Lins - Bolsista da RLE (2014-2015)

Dafiana Carlos - Capa da RLE

Indexada em:

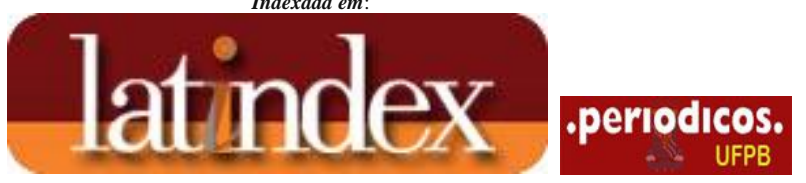

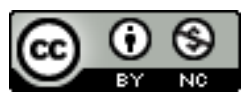

RLE está sob licença Creative Commons Atribuição-Uso não-comercial 3.0 Brasil License. Revista Lugares de Educação [RLE] Periódico eletrônico do Departamento de Educação (CCHSA/UFPB) ISSN 2237-1451 [eletrônico] Bananeiras, Paraíba, Brasil Dr. Eduardo Jorge Lopes da Silva Editor-chefe 
V. 5, N. $11(2015$

MULTITEMÁTICO

SUMÁRIO

CRÉDITOS

Créditos

RLE RLE

EDITORIAL

Editorial

Eduardo Jorge Lopes da Silva

ARTIGOS - FORMAÇÃO DE PROFESSORES E PRÁTICAS PEDAGÓGICAS

O SIGNIFICADO DO TRABALHO: UM ESTUDO COM PROFESSORES DE ADMINISTRAÇÃO EM UMA UNIVERSIDADE

Zelia Miranda kilimnik, Mário Teixeira Reis Neto, Gabriela Silva dos Santos, Valéria Duarte Malta, Marcos Ferreira Santos

“... e a experiência, conta!: reflexões sobre a trajetória pessoal e profissional de uma formanda em pedagogia.

Iranuzia Maria da Silva Costa, Fabiana Pinto de Almeida Bizarria

ARTIGOS - TEMAS DIVERSOS EM EDUCAÇÃO

"E AÍ ELE CHORA DENTRO DELE": PERCEPÇÕES INFANTIS SOBRE VIOLÊNCIA E MAL ESTAR NAS RELAÇÕES ESCOLARES

Fernanda Telles Márques, Thaís Resende Araújo Borges Bonfim, Rafaell Carneiro Silva

Kellen Cristina Martins Mayer, Erica Santana Viana da Silva, José Anchieta de Araujo

PERCEPÇÃO DOS ALUNOS DO ENSINO FUNDAMENTAL SOBRE OS INSETOS ANTES E APÓS AULAS PRÁTICAS: UM CASO DE ESTUDO NO MUNICÍPIO DE URUARÁ-PARÁ, PDF BRASIL

Reinaldo Lucas Cajaiba, Wully Barreto Silva

O USO DO LIVRO DIDÁTICO DE CIÊNCIAS POR ALUNOS DO ENSINO FUNDAMENTAL DE FORMOSA, GOIÁS PDF 
OBJETIVOS EDUCACIONAIS DE BLOOM, RESULTADOS DE APRENDIZAGEM E INSTRUMENTOS DE AVALIAÇÃO FORMATIVA NO ENSINO SUPERIOR: UMA REFLEXÃO INTEGRATIVA

MOTIVOS POR LOS QUE SE ESTUDIA INGLES COMO SEGUNDA LENGUA EN ESPAÑA. LA EXPERIENCIA DEL APRENDIZAJE EN LAS ESCUELAS OFICIALES DE IDIOMAS (EOI)

Carmina Pérez Pérez, Manuela Avilés Hernández, Juan Luis Monreal Pérez

Comunidades de Aprendizaje y sus contextos de origen

ARTIGOS - POLÍTICAS PÚBLICAS E GESTÃO EDUCACIONAL

GESTÃO SOCIAL DOS CONSELHOS ESCOLARES

PDF

Gislene Silva Dutra, Maria Lúcia Miranda Afonso

ARTIGOS - LETRAS E LINGUÍSTICA

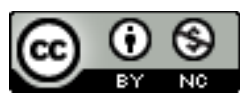

RLE está sob licença Creative Commons Atribuição-Uso não-comercial 3.0 Brasil License. 


\section{APRENDIZAGEM DE LÍNGUAS COM NARRATIVAS DIGITAIS: UMA EXPERIÊNCIA NO ENSINO DO INGLÊS PARA FINS ESPECÍFICOS}

Resumo: Este artigo descreve uma experiência interdisciplinar e internacional de criação de narrativas digitais para a aprendizagem do inglês num contexto de ensino da língua para fins específicos. A colaboração foi feita entre a Faculdade de Educação da Unicamp, Brasil; e o grupo de pesquisa CAMILLE, do Departamento de Linguística Aplicada da Univesitat Politènica de València, Espanha; dentro de um convênio de cooperação científica internacional entre ambos os países, no qual foram desenvolvidos recursos educativos e metodologias para o ensino do inglês e do espanhol. As narrativas digitais podem ser entendidas como os breves filmes resultantes da prática de combinar múltiplos modos de tecnologia, como fotografias, texto, música, narração de voz e clips de vídeo para produzir uma narrativa emotiva e profunda. Os alunos colaboram nas diferentes etapas do projeto de criação das narrativas digitais combinando a antiga arte de contar histórias com a relativamente nova prática de combinar elementos multimodais como imagens, vídeos e efeitos visuais ou sonoros, bem como uma trilha sonora, para criar uma narrativa contada desde uma perspectiva única, profunda, original e pessoal. Essa proposta pedagógica permite promover o trabalho colaborativo e a autoria múltipla, já que o sucesso final do grupo será o resultado dos esforços individuais e colaborativos de cada um dos membros do grupo. Neste projeto, o trabalho interdisciplinar de criação de narrativas digitais foi feito com base em três áreas do conhecimento: a linguagem audiovisual e as TIC, com a aplicação de técnicas audiovisuais para a produção dos vídeos; a engenharia aeroespacial, já que os temas tratados tinham a ver com conteúdos específicos dessa área; e a aprendizagem do inglês para fins específicos. Os principais resultados do trabalho interdisciplinar realizado foram altos níveis de engajamento e de motivação dos estudantes; a aquisição e construção de conhecimentos e habilidades do campo da engenharia aeroespacial através da aprendizagem colaborativa e autônoma; e a prática e desenvolvimento de destrezas e competências digitais e linguísticas, bem como o pensamento crítico e a capacidade de solução de problemas.

Palavras-chave: Narrativa digital. Inglês para fins específicos. Engenharia aeroespacial. TIC. Letramentos

\section{Introdução}

Este artigo descreve uma experiência interdisciplinar e internacional de grande potencial educacional: a criação de narrativas digitais para a aprendizagem do inglês num contexto de ensino da língua para fins específicos. As narrativas digitais (em inglês, digital stories) podem ser entendidas como os filmes resultantes da prática de combinar múltiplos modos de tecnologia, como fotografias, texto, música, narração de voz e clips de vídeo para produzir uma narrativa emotiva e profunda (Castañeda, 2013).

Os alunos trabalham colaborativamente nas diferentes etapas do projeto de criação das narrativas digitais, para criar um vídeo breve (de uns 4 minutos de duração) que faz 
com que pessoas comuns possam compartilhar aspetos da sua vida pessoal e expressar sua própria visão do mundo, em maneira multimodal e formato audiovisual (Robin, 2012), com uma alta implicação de fatores emocionais. Assim, uma narrativa digital é o resultado de combinar a antiqüíssima arte de contar histórias com a relativamente nova prática de combinar elementos multimodais como imagens, vídeos e efeitos visuais ou sonoros, bem como uma trilha sonora, para criar uma narrativa contada desde uma perspectiva única, profunda, original e pessoal.

Como proposta pedagógica, a elaboração de narrativas digitais pode ser feita em praticamente todas as áreas de conhecimento. Além disso, as narrativas digitais contribuem a fomentar e desenvolver uma ampla variedade de letramentos e competências, como o letramento digital, a criatividade e o pensamento crítico, entre outros. Além do mais, no caso das narrativas digitais criadas em grupos, essa proposta pedagógica permite promover o trabalho colaborativo e a autoria múltipla, já que o sucesso final do grupo será o resultado dos esforços individuais e colaborativos de cada um dos membros do grupo.

Segundo Lambert (2002), toda narrativa digital completa e bem feita costuma ter sete elementos principais: ponto de vista, pergunta dramática, conteúdo emocional, voz do narrador, trilha sonora, economia narrativa e ritmo da narração. Esses elementos podem ser classificados em duas fases da criação das narrativas: a fase de escrita, e a fase de elaboração posterior.

A fase de escrita inclui os seguintes elementos: ponto de vista, pergunta dramática, conteúdo emocional e economia narrativa. Quanto à fase de elaboração posterior, os elementos inclusos nela são: o ritmo, a voz do narrador e a trilha sonora. O ponto de vista será determinado pelos motivos pelos quais o autor ou autores da narrativa querem contar uma história, o objetivo perseguido, a audiência que receberá e interpretará a narrativa, e a mensagem a ser transmitida. Ao início da narrativa, o autor faz uma pergunta dramática, de modo direto ou indireto, para criar suspense e para chamar à atenção da audiência.

O conteúdo emocional faz com que o interesse e a curiosidade da audiência aumentem gradativamente, e cria uma maior empatia entre o autor ou autores e o receptor ou receptores. A voz do narrador ou dos narradores facilita a transmissão da mensagem por parte do autor ou autores. A trilha sonora, embora opcional, é um elemento complementário importante porque contribui a reforçar a mensagem, motivo pelo qual 


\section{Ana Sevilla-Pavón \\ Tania Lucía Maddalena \\ Universitat de València, Espanha}

deve ser escolhida cuidadosamente para evitar que um volume excessivo o a presença de letra que possa interferir negativamente na compreensão da história. A economia narrativa é outro elemento essencial, pois a sua função é evitar o excesso de informação, o que ajuda à audiência a focar a sua atenção na mensagem central da narrativa. Por último, o ritmo é um elemento que tem a ver não somente com a velocidade com que a história é contada, mas também com a velocidade e quantidade de imagens ou vídeos que aparecem em sincronia com a voz no narrador ou narradores. É muito importante que a narrativa digital tenha um ritmo apropriado, nem muito rápido nem muito divagar, para que a narrativa seja compreensível e, ao mesmo tempo, interessante e divertida.

A criação de narrativas digitais com fins educativos permite misturar as Tecnologias da Informação e das Comunicações (TIC) com a antiqüíssima tradição de contar histórias para transmitir o conhecimento. É uma prática herdeira das práticas ancestrais de contagem de histórias e lendas para a comunicação e transmissão oral e síncrona do saber. Ao mesmo tempo, é uma prática social que pode ser considerada moderna e atual, pois incorpora as TIC e se beneficia do uso de uma grande variedade de dispositivos eletrônicos que possibilitam a comunicação multimodal assíncrona para 0 compartilhamento e o acesso ao conhecimento e a informação em tempos e lugares diversos.

As narrativas tinham no passado e ainda têm uma importância enorme para a humanidade, não somente como elementos decisivos na transmissão e difusão do conhecimento, mas também devido ao fato de ajudar às pessoas a construírem significados a partir das experiências vitais (Bruner, 1996, 2003; Shank, 1990). Essas experiências que são compiladas em forma de narrativas são elementos essenciais dos processos de ensino e aprendizagem (Shank, 1990; Zull, 2002). Além disso, nos contextos educacionais as histórias contribuem a criar conexões mentais entre os novos conteúdos e os conhecimentos prévios dos estudantes (Shank, 1990). Essas características fazem com que as histórias sejam mais divertidas e memoráveis (Shank, 1990; Rex, Murnen, Hobbs \& McEache, 2002).

Contar e compartilhar narrativas também ajuda aos estudantes a compreender-se melhor os unos aos outros e a desenvolverem a capacidade de se colocar no lugar do outro (Lowenthal, 2008), pois "não é no silêncio que os homens se fazem, mas na palavra, no trabalho, na ação-reflexão" (Freire, 1987, p. 78). Assim, o fato dos indivíduos 
trabalharem juntos e compartilharem informações ou visões pessoais faz com que se identifiquem os uns com os outros (Lowenthal \& Dunlap, 2010). Isso torna a aprendizagem por meio das narrativas uma atividade de reflexão que permite aos estudantes o desenvolvimento pessoal e a expressão das suas opiniões, idéias e percepções pessoais, que estão presentes nas suas escolhas e no modo em que as suas respectivas narrativas são apresentadas.

Neste projeto, o trabalho interdisciplinar de criação de narrativas digitais foi feito com base em três áreas do conhecimento: a linguagem audiovisual e as TIC, com a aplicação de técnicas audiovisuais para a produção dos vídeos; a engenharia aeroespacial, já que os temas tratados tinham a ver com conteúdos específicos dessa área; e a aprendizagem do inglês para fins específicos. A colaboração foi feita entre a Faculdade de Educação da Unicamp, Brasil; e o grupo de pesquisa CAMILLE, do Departamento de Linguística Aplicada da Univesitat Politènica de València, Espanha; dentro de um convênio de cooperação científica internacional entre ambos os países, no qual foram desenvolvidos recursos educativos e metodologias para o ensino do inglês e do espanhol. Alguns desses recursos e metodologias foram usados num curso presencial de "inglês técnico" de 60 horas oferecido na Facultad de Ingeniería del Diseño da Universitat Politècnica de València, na Espanha.

O objetivo do curso era a familiarização dos estudantes de um curso de engenharia aeroespacial com as formas léxico-gramaticais da língua inglesa, bem como o conhecimento de temas específicos da engenharia. Para a elaboração colaborativa de narrativas digitais sobre temas relacionados com a engenharia aeroespacial os estudantes fizeram várias atividades: uma WebQuest de introdução ao projeto; procurar e selecionar informações em relação ao tema escolhido; criar um roteiro; selecionar os elementos audiovisuais a serem incluídos; escolher o software; gravar a narração em base ao roteiro e sincronizá-la com as imagens; montar o vídeo, adicionando os créditos e a legenda; compartilhar o vídeo no fórum do ambiente virtual de aprendizagem (AVA) PoliformaT; fazer uma apresentação oral do processo criativo; redigir um diário de reflexão; e avaliar o trabalho próprio e dos outros estudantes.

Os principais resultados do trabalho interdisciplinar realizado foram altos níveis de engajamento e de motivação dos estudantes, que viraram autores e coautores dos próprios conteúdos educativos; a aquisição e construção de conhecimentos e habilidades 
do campo da engenharia aeroespacial através da aprendizagem colaborativa e autônoma; e a prática e desenvolvimento de destrezas e competências digitais e linguísticas, bem como o pensamento crítico e a capacidade de solução de problemas. Os resultados, que foram considerados muito positivos pelos professores e alunos, são um bom exemplo do grande potencial educacional da inclusão de atividades interdisciplinares no ensino superior.

\section{Objetivos}

O objetivo principal da proposta de criação colaborativa e uso de narrativas digitais em inglês foi contribuir para a familiarização dos estudantes de um curso de engenharia aeroespacial com as formas léxico-gramaticais da língua inglesa.

Os objetivos secundários foram o fomento de aprendizagem de temas específicos da engenharia, o estímulo ao desenvolvimento de letramentos em língua inglesa, a promoção do engajamento e da motivação dos estudantes, o incentivo da aquisição e construção de conhecimentos e habilidades do campo da engenharia aeroespacial através da aprendizagem colaborativa e autônoma; e o estímulo à prática e desenvolvimento de destrezas e competências digitais e linguísticas, bem como o pensamento crítico e a capacidade de solução de problemas.

\section{Método}

Para a elaboração colaborativa de narrativas digitais sobre temas relacionados com a engenharia aeroespacial os estudantes tiveram que completar várias atividades, usando diferentes recursos, como: computadores com acesso à internet e com diversos tipos de software gratuito, microfones e datashow.

Primeiramente, eles completaram as atividades de uma WebQuest introdutória (Figura 1), na qual os estudantes acessaram informações e recursos multimodais sobre a temática do projeto e responderam várias questões. Depois, procuraram informações sobre o tema escolhido por cada um dos grupos. Após ter feito isso, os estudantes escreveram os roteiros, de maneira colaborativa. 


\section{Creating your own digital story}

\begin{tabular}{|c|c|}
\hline Welcome & *Welcome \\
\hline Introduction & \multirow{12}{*}{$\begin{array}{l}\text { Welcome: Creating your own digital story } \\
\text { Description: This WebQuest is an introduction to digital storytelling for first year students of aerospace engineering } \\
\text { who are registered in the subject "Technical English" offered at the Universitat Politècnica de València (UPV), Spain. } \\
\text { Grade Level: College / Adult } \\
\text { Curriculum: English / Language Arts } \\
\text { Keywords: Technical English, aerospace engineering, digital storytelling. } \\
\text { Author(s): Belén Serra, Ana Sevilla }\end{array}$} \\
\hline Task & \\
\hline Process & \\
\hline Evaluation & \\
\hline Conclusion & \\
\hline Teacher Page & \\
\hline About Author(s) & \\
\hline Evaluate WebQuest & \\
\hline Reviews & \\
\hline Statistics & \\
\hline Export WebQuest & \\
\hline Share This WebQuest & \\
\hline & $\begin{array}{l}\text { The Public URL for this WebQuest: } \\
\text { htttp://zunal.com/webquest.php?w= } 165788\end{array}$ \\
\hline
\end{tabular}

Figura 1. WebQuest introdutória ao projeto de criação de narrativas digitais. Fonte: Serra Cámara e Sevilla Pavón, 2012.

A seguinte etapa teve a ver com a seleção dos elementos audiovisuais a serem incluídos na narrativa digital, bem como a escolha do software. Seguidamente, os estudantes fizeram a gravação de voz em base ao roteiro e sincronizaram a narração com os recursos audiovisuais previamente selecionados. Uma vez feito isso, a seguinte tarefa foi fazer a montagem (Figura 2) das narrativas em forma de vídeo legendado e com os créditos respectivos. 

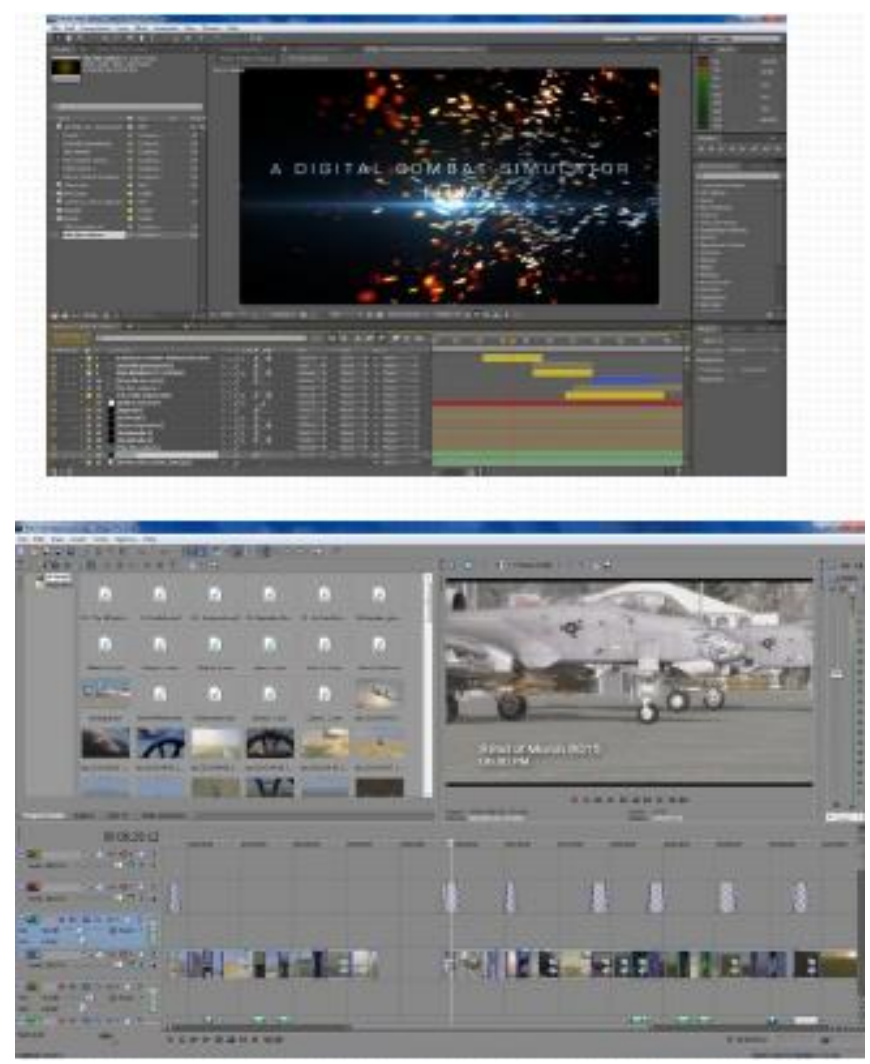

Figura 2. Exemplo de criação de sequencia de vídeo para a criação de narrativas digitais. Fonte: Alunos de Engenharia Aerospacial da Universitat de València, Espanha.

Posteriormente, os alunos disponibilizaram seus vídeos por meio de um link que foi compartilhado no fórum do ambiente virtual de aprendizagem (AVA) usado na UPV, PoliformaT (Figura 3). Acessando o link, os estudantes tinham a opção de assistir os vídeos online (streaming) e escrever seus comentários, críticas e sugestões em cada uma das entradas do fórum, as quais correspondiam às diferentes narrativas digitais. 


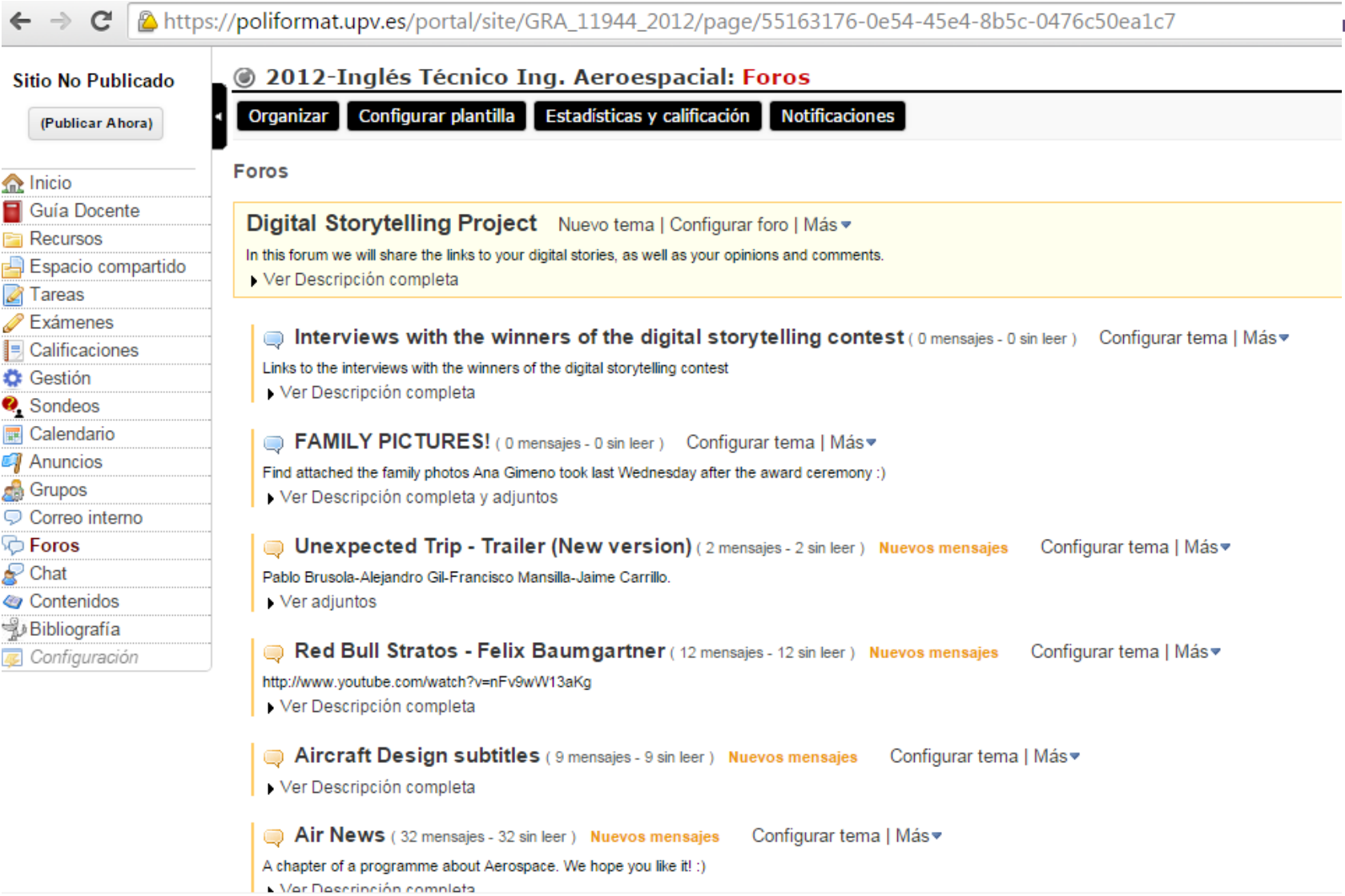

Figura 3. Exemplo de interações no fórum online do projeto de criação de narrativas digitais. Fonte: AVA PoliformaT, Universitat de València, Espanha.

Assim que todos os grupos tinham assistido os vídeos dos seus colegas, cada grupo fez uma apresentação oral do processo criativo, na qual eles explicavam passo a passo o processo de criação das narrativas digitais e tiravam as dúvidas dos colegas em relação ao mesmo (Figura 4). As apresentações orais foram feitas com apoios visuais multimodais (Microsoft Power Point, Prezi, fotografias, clips de vídeo, etc.) 


\section{PROBLEMS DURING CREATIVE}

\section{STAGE}

- Only one group member had the necessary skills to play the special hardware. Handling the aircraft properly using the flight simulator requires lots of practice.

- As consequence each member was responsible for specific tasks

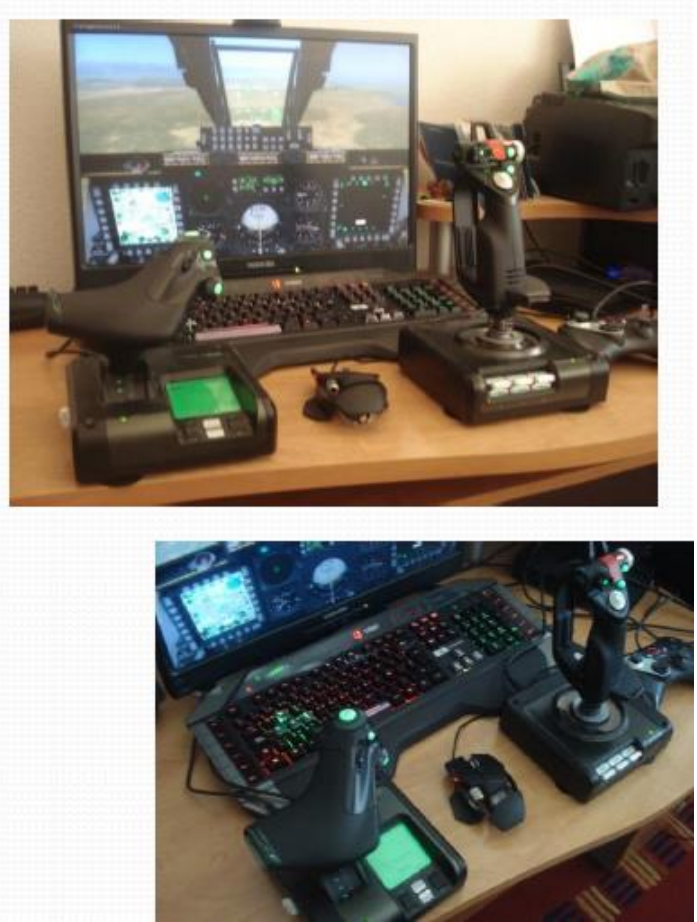

Figura 4. Exemplo de apoio visual (com Power Point e fotografias) para a apresentação oral do processo de criação de narrativas digitais. Fonte: Alunos de Engenharia Aerospacial da Universitat de València, Espanha.

A fonte documental principal do processo criativo foi o diário de reflexão que os estudantes tinham escrito ao longo do processo. Finalmente, os estudantes avaliaram o próprio trabalho e o trabalho dos outros estudantes, usando duas planilhas de avaliação e de autoavaliação: uma planilha para as narrativas digitais e outra para as apresentações orais (Figura 5). 


\begin{tabular}{|c|c|c|c|c|c|c|c|}
\hline \multicolumn{8}{|c|}{ Assessment sheet for the making-of presentations (Practice 9) } \\
\hline \multirow{2}{*}{$\begin{array}{l}\text { EVALUATING YOUR CLASSMATES: } \\
\text { 9-10= Outstanding / 6-8= Satisfactory / } 4-5= \\
\text { Needs improvement } / 1-3=\text { Very poor }\end{array}$} & \multicolumn{7}{|c|}{ SCORES } \\
\hline & 1) Air News & $\begin{array}{l}\text { 2) Humans vs. } \\
\text { Aliens }\end{array}$ & $\begin{array}{l}\text { 3) Unexpected Trip } \\
\text { (Trailer) }\end{array}$ & $\begin{array}{l}\text { 4) Hybrids: a } \\
\text { new era of } \\
\text { flying }\end{array}$ & $\begin{array}{l}\text { 5) A Trip to The } \\
\text { Stars }\end{array}$ & $\begin{array}{l}\text { 6) One-way } \\
\text { Trip }\end{array}$ & $\begin{array}{c}\text { 7) } \\
\text { Aerodynamics }\end{array}$ \\
\hline Structure / Organisation & 8 & 7 & 8 & 8 & 5 & 8 & 9 \\
\hline Use of presentation time & 9 & 7 & 7 & 7 & 5 & 6 & 6 \\
\hline Originality & 7 & 8 & 9 & 6 & 7 & 7 & 6 \\
\hline Clarity & 9 & 6 & 7 & 8 & 6 & 7 & 8 \\
\hline Pronunciation & 9 & 7 & 9 & 9 & 5 & 8 & 8 \\
\hline Linguistic skills and level of English & 8 & 7 & 9 & 10 & 6 & 9 & 8 \\
\hline Communicative and presentation skills & 8 & 5 & 7 & 9 & 5 & 7 & 7 \\
\hline Resources & 6 & 8 & 7 & 6 & 7 & 7 & 7 \\
\hline Log & 7 & 4 & 6 & 7 & 4 & 5 & 7 \\
\hline Creative process & 7 & 7 & 7 & 8 & 6 & 7 & 8 \\
\hline
\end{tabular}

\begin{tabular}{|l|l|}
\hline \multicolumn{1}{|c|}{ TITLE } & \multicolumn{1}{c|}{ COMMENTS: Groups 1 to 7 } \\
\hline 1) Air News & $\begin{array}{l}\text { Although they have had less time to present, I think that they have got a good result. Maybe if they had been more time presenting, } \\
\text { their presentation would have been boring like others. I think that Spanair's accident is an interesting topic and they have done a great } \\
\text { job. }\end{array}$ \\
\hline 2) Humans vs. Aliens & $\begin{array}{l}\text { During the presentation, they have had technical problems and because of it, the presentation has been a bit boring. However, they } \\
\text { have spoken very slowly and, in my opinion, they could have improved the presentation. }\end{array}$ \\
\hline $\begin{array}{l}\text { 3) Unexpected Trip } \\
\text { (Trailer) }\end{array}$ & $\begin{array}{l}\text { Their pronunciation was outstanding. In addition, I have to admit that they did a great job appearing in the video like us. However, } \\
\text { during the presentation, they haven't convinced me that making a trailer was better than making a video and I don't find a relation } \\
\text { between their trailer and the Aerospace Engineering. }\end{array}$ \\
\hline $\begin{array}{l}\text { 4) Hybrids: a new era } \\
\text { of flying }\end{array}$ & $\begin{array}{l}\text { Their English level was one of the best. Furthermore, the presentation hasn't been boring and they have included everything that we } \\
\text { needed to know how they made the digital story. }\end{array}$ \\
\hline 5) A Trip to The Stars & $\begin{array}{l}\text { In my opinion, they could have used the microphone or spokena bit louder. I also think that a 10 minutes presentation doesn't require } \\
\text { having a paper to read what you are going to say, as other groups did. }\end{array}$ \\
\hline 6) One-way Trip & $\begin{array}{l}\text { Although they have said that their presentation wasn't going to be long, they have used a lot of time showing the whole digital story } \\
\text { that we had already seen.I think that they could have explained better the making-of instead. }\end{array}$ \\
\hline 7) Aerodynamics & $\begin{array}{l}\text { In my opinion, their presentation was very interesting. Maybe it was a bit long, but their video and their presentation are one of the } \\
\text { bests. }\end{array}$ \\
\hline
\end{tabular}

Figura 5. Exemplo de planilha de avaliação das apresentações orais do processo de criação de narrativas digitais. Fonte: Alunos de Engenharia Aerospacial da Universitat de València, Espanha.

\section{Resultados observados}

Os principais resultados do trabalho interdisciplinar realizado foram altos níveis de engajamento e de motivação dos estudantes, que viraram autores e coautores dos próprios conteúdos educativos; a aquisição e construção de conhecimentos e habilidades do campo da engenharia aeroespacial através da aprendizagem colaborativa e autônoma; e a prática e desenvolvimento de destrezas e competências digitais e linguísticas, bem como o pensamento crítico e a capacidade de solução de problemas. Esses resultados, que foram considerados muito positivos pelos professores e pelos alunos, são um bom exemplo do grande potencial educacional da inclusão de atividades interdisciplinares no ensino superior.

Esse projeto pode ser considerado como inovador pela sua grande interdisciplinaridade, pois foram combinados conhecimentos e destrezas de diversas 
disciplinas, como a engenharia aeroespacial, a comunicação audiovisual e a língua inglesa para fins específicos.

Os conhecimentos da área da engenharia aeroespacial tiveram a ver principalmente com o léxico usado para falar dos diferentes temas: a carreira profissional de um engenheiro aeroespacial, a exploração espacial, o design espacial, eventos e personagens reais ou ficcionais da história da aviação, tipos de aviões e segurança aérea.

Os conhecimentos em relação à comunicação audiovisual foram os relacionados com a criação e edição de vídeos, principalmente com o uso de diferentes tipos de software, como iMovie e Microsoft Movie Maker, bem como vários tipos de software para a gravação de som, como Audacity ou o gravador de som do Windows.

Finalmente, os conhecimentos em língua inglesa adquiridos graças ao projeto tiveram a ver com os descritores do Quadro Comum Europeu de Referência de nível intermediário-alto ou B2, bem como com os objetivos pedagógicos estabelecidos na ementa do curso, pois os alunos praticaram as quatro destrezas principais em língua inglesa: leitura, escrita, compreensão oral e expressão oral, além da gramática e o vocabulário.

\section{Considerações finais}

A experiência interdisciplinar e internacional de a criação de narrativas digitais para a aprendizagem do inglês num contexto de ensino da língua para fins específicos é um exemplo do modo em que várias áreas do conhecimento podem ser combinadas de forma a favorecer a aprendizagem integral e significativa.

Assim, as contribuições das áreas de a linguagem audiovisual e de TIC, a engenharia aeroespacial e o inglês para fins específicos fizeram com que os estudantes aprendessem diferentes técnicas audiovisuais de produção e edição de vídeo, léxico e conteúdos da engenharia aeroespacial, ao tempo que tiveram inúmeras oportunidades de prática de várias destrezas em língua inglesa, bem como de compreensão e de expressão orais e escritas.

O projeto foi valorado muito positivamente pelos estudantes e professores envolvidos, bem como pelas instituições participantes no projeto: a Unicamp no Brasil e a UPV na Espanha. Graças ao convênio de cooperação científica internacional subscrito 
entre ambos os países, foram desenvolvidos recursos educativos e metodologias para ensino do inglês e do espanhol no Brasil e na Espanha, os quais foram disponibilizados de maneira gratuita através de diferentes repositórios de objetos de aprendizagem para a sua reutilização e atualização periódica por parte dos seus criadores bem como de outros docentes.

O objetivo principal da proposta de criação colaborativa e uso de narrativas digitais em inglês foi atingido, pois o projeto permitiu a familiarização dos estudantes com as formas léxico-gramaticais da língua inglesa por meio das inúmeras possibilidades de prática significativa e contextualizada nas diferentes etapas do projeto.

Quanto aos objetivos secundários, esses também foram atingidos, já que o projeto fomentou a aprendizagem de temas específicos da engenharia, como a carreira profissional de um engenheiro aeroespacial, a exploração espacial, o design espacial, eventos e personagens reais ou ficcionais da história da aviação, tipos de aviões e segurança aérea.

Além disso, o projeto contribuiu para desenvolvimento de letramentos e competências em língua inglesa, como o letramento digital e crítico. Do mesmo modo, o projeto favoreceu o engajamento e a motivação dos estudantes, facilitando a aquisição e construção de conhecimentos e habilidades do campo da engenharia aeroespacial através da aprendizagem colaborativa e autônoma; e fomentou a prática e desenvolvimento de destrezas e competências digitais e linguísticas, bem como o pensamento crítico, a criatividade e a capacidade de solução de problemas.

\section{Referências}

BRUNER J. Making Stories: Law, Literature, Life. Cambridge, MA: Harvard University Press, 2003.

BRUNER, J. The Culture of Education. Cambridge, MA: Harvard University Press, 1996. FREIRE, P. Pedagogia do Oprimido. Rio de Janeiro: Paz e Terra, 1987.

LAMBERT, J. Digital Storytelling: capturing lives, creating community. Berkeley: Digital Diner Press, 2002.

LOWENTHAL, P. R. Online faculty development and storytelling: An unlikely solution to improving teacher quality. MERLOT Journal of Online Learning and Teaching, 4(3), 349- 
356. Disponível em http://jolt.merlot.org/vol4no3/lowenthal 0908.pdf. Acesso em: 04.03.2014, 2008.

LOWENTHAL, P. R. \& DUNLAP, J. C. From pixel on a screen to real person in your students' lives: Establishing social presence using digital storytelling. Internet and Higher Education, n. 13, 70-72, 2010.

Robin, B. R. The Educational Uses of Digital Storytelling. Disponível em: $<$ http://digitalliteracyintheclassroom.pbworks.com/f/Educ-Uses-DS.pdf>. Acesso em: 04.03.2014, 2012.

REX, L. A.; MURNEN, T.; HOBBS, J.; MCEACHEN, D. Teachers' pedagogical stories and the shaping of classroom participation: "The Dancer" and "Graveyard Shift at the 7-11". American Education Research Journal, n. 39, v. 3, p. 765-796, 2002.

SCHANK, R. C. Tell me a story: Narrative and intelligence. Evanston, IL: Northwestern University Process, 1990.

Serra Cámara, A. \& Sevilla Pavón, A. WebQuest introdutória para a criação de narrativas digitais. Disponível em: http://zunal.com/webquest.php?w=165788, 2012.

ZULL, J. The Art of Changing the Brain. Sterling, VA: Stylus Publishing, 2002.

Recebido em: 04/05/2015

Aprovado em: 20/05/2015 